\title{
Produtividade de feijoeiro de inverno submetido à dessecação com paraquat na pré-colheita
}

\author{
Claudinei Kappes ${ }^{1}$, Orivaldo Arf ${ }^{2}$, Marcelo Valentini Arf', João Paulo Ferreira ${ }^{3}$, Andrews Molnar Alcalde ${ }^{4}$, \\ José Roberto Portugal
}

\begin{abstract}
RESUMO
O conhecimento da época e da dose de aplicação de dessecante, em pré-colheita do feijoeiro, é de extrema importância para se evitarem perdas na produtividade da cultura. Diante disso, o objetivo deste trabalho foi avaliar a produtividade de feijoeiro de inverno, após aplicação do dessecante paraquat em diferentes épocas (30; 35; 40 e 45 dias após o início do florescimento - DAF) e das doses (0; 200; 400 e $\left.600 \mathrm{~g} \mathrm{ha}^{-1}\right)$, em pré-colheita. O experimento foi conduzido no período de outono/inverno de 2010, em Selvíria, Mato Grosso do Sul. Os tratamentos foram dispostos em delineamento experimental de blocos ao acaso, em esquema fatorial 4 x 4 (épocas de aplicação x doses do herbicida), com quatro repetições. O aumento das doses de paraquat, até os $35 \mathrm{DAF}$, aumentou de forma linear o percentual de sementes defeituosas, enquanto as sementes tiveram sua massa reduzida linearmente, até os 40 DAF. A produtividade do feijoeiro não foi afetada pela aplicação de paraquat a partir dos $35 \mathrm{DAF}$, ao contrário do incremento da dose, que provocou redução linear desse parâmetro.
\end{abstract}

Palavras-chave: Phaseolus vulgaris L., sementes, herbicida.

\begin{abstract}
Yield of winter common bean: effect of desiccation with paraquat in pre-harvest

Knowledge on time and rate of desiccant application in pre-harvest of common bean is important to prevent yield losses. The objective of this work was to evaluate the yield of the winter common bean after application of paraquat as desiccant at different times $(30 ; 35 ; 40$ and 45 days after the beginning of flowering - DAF) and rates $(0 ; 200 ; 400$ e 600 $\mathrm{g} \mathrm{ha}^{-1}$ ) in pre-harvest. The experiment was conducted in the fall/winter growing season of 2010, in Selvíria, Mato Grosso do Sul State, Brazil. The treatments were arranged in a randomized block design in a $4 \mathrm{x} 4$ factorial (application times $\mathrm{x}$ herbicide rates), with four replications. The increase in rates of paraquat up to 35 DAF increased linearly the percentage of defective seeds, whereas the seed mass was reduced linearly up to 40 DAF. The yield of the common bean was not affected by paraquat application from the $35 \mathrm{DAF}$, but the increase in the rate caused linear reduction in this parameter.
\end{abstract}

Key words: Phaseolus vulgaris L., seeds, herbicide.

Recebido para publicação em 27/08/2010 e aprovado em 20/12/2011

'Engenheiros-Agrônomos, Mestres. Doutorandos em Agronomia, Universidade Estadual Paulista (UNESP), Av. Brasil, 56, Caixa Postal 31, Centro, 15385-000, Ilha Solteira, São Paulo,Brasil.kappes.agro@gmail.com; marceloarf@hotmail.com

${ }^{2}$ Engenheiro-Agrônomo, Doutor. Departamento de Fitotecnia, Tecnologia de Alimentos e Sócio-Economia, Universidade Estadual Paulista (UNESP), Av. Brasil, 56, Caixa Postal 31, Centro, 15385-000, Ilha Solteira, São Paulo, Brasil. arf@agr.feis.unesp.br

${ }^{3}$ Engenheiro-Agrônomo. Mestrando em Agronomia, Universidade Estadual Paulista (UNESP), Av. Brasil, 56, Caixa Postal 31, Centro, 15385-000, Ilha Solteira, São Paulo, Brasil. ferreirajpferreira@gmail.com

${ }^{4}$ Acadêmicos de Agronomia. Universidade Estadual Paulista (UNESP), Av. Brasil, 56, Caixa Postal 31, Centro, 15385-000, Ilha Solteira, São Paulo, Brasil. andrews_molnar@hotmail.com; jr_portugal@hotmail.com

Rev. Ceres, Viçosa, v. 59, n.1, p. 56-64, jan/fev, 2012 


\section{INTRODUÇÃO}

A cultura do feijoeiro, explorada quase exclusivamente por pequenos agricultores, atualmente está sendo realizada também em maiores áreas por agricultores que adotam altas tecnologias. Avanços nas áreas de pesquisa genética, utilização de sistemas de irrigação e realização de colheita mecanizada têm contribuído para elevar a produtividade e a qualidade das lavouras de feijão (Miguel, 2003). No entanto, algumas características intrínsecas à planta, como maturação desuniforme em cultivares de hábito de crescimento indeterminado, entrenós basais curtos, associados à baixa altura de inserção de vagens, contribuem para as perdas qualitativas e quantitativas de sementes, como também limitam a colheita com automotrizes (Teixeira et al., 1999).

$\mathrm{O}$ atraso da colheita torna as sementes de feijão susceptíveis à deterioração e à invasão de micro-organismos, notadamente fungos, por interferência de fatores do meio ambiente, como temperatura, umidade relativa do ar e precipitações, principalmente, em áreas de semeadura escalonada e irrigadas por sistema de pivô central. Outro problema relacionado com o atraso da colheita refere-se ao aumento de deiscência de vagens e, consequentemente, das perdas anteriores à colheita. Entretanto, adiantandose a colheita, a haste estará verde e túrgida e, ao entrar no cilindro da colhedora, esse material será misturado às sementes, causando a elevação da umidade, o que pode gerar problemas futuros no armazenamento (Marchiori Júnior et al., 2002).

A aplicação de dessecantes, em pré-colheita da cultura, que preservem a produtividade e a qualidade da semente, é uma técnica bastante interessante na solução deste problema. A dessecação faz-se com o uso de produtos químicos apropriados e resulta em rápida secagem de todas as partes da planta. Alguns autores relatam que os herbicidas utilizados na pré-colheita permitem uniformizar a maturação, proporcionando uma secagem uniforme das vagens e sementes; antecipam a colheita; não prejudicam a produtividade, pois não induzem a deiscência das vagens; não afetam a germinação nem o vigor das sementes; diminuem o teor de água das sementes e controlam as plantas daninhas (Zagonel et al., 2002).

Dentre os dessecantes disponíveis no mercado, o herbicida paraquat merece destaque, pois tem sua eficiência comprovada em várias culturas. Nas plantas, o paraquat atua rapidamente, por contato, causando forte toxicidade, após algumas horas da aplicação. Esse herbicida atinge diretamente o sistema fotossintético da planta (Ekmekci \& Terzioglu, 2005). O mecanismo de ação dá-se por meio do bloqueio de elétrons da fotossíntese, impedindo a redução do $\mathrm{NADP}^{+}$à $\mathrm{NADPH}_{2}$. Dessa forma, ocorre um acúmulo de elétrons e de radicais livres no cloroplasto, causando sérios danos ao metabolismo celu- lar, como danos estruturais no DNA, proteínas, lipídios e pigmentos (Benavides et al., 2000). Estes radicais são instáveis e sofrem auto-oxidação, resultando radicais superóxidos, hidroxilas e oxigênio singleto ou radicais livres. Estes, por sua vez, são reativos com os lipídios das membranas celulares, promovendo sua peroxidação. Com a degradação das membranas, há um vazamento do suco celular e morte do tecido (Vargas et al., 1999), ocasionando a dessecação das plantas em curto espaço de tempo.

A prática da dessecação para minimizar os problemas do retardamento da colheita tem sido observada em diversas culturas (Miguel, 2003; Lacerda et al., 2005). Entretanto, na cultura do feijoeiro, o emprego de dessecantes é assunto relativamente novo; todavia, o interesse por essa prática vem aumentando gradativamente, em algumas regiões produtoras, com o objetivo de reduzir os inconvenientes causados à colheita (Santos et al., 2005), conforme mencionados. Desse modo, pouco se sabe a respeito dos efeitos da aplicação de paraquat em précolheita sobre a produtividade do feijoeiro.

Para o feijoeiro, as decisões relacionadas com a época ideal para aplicação dos dessecantes são tomadas, considerando-se o estádio de degenerescência das folhas, a mudança de cores das vagens, o teor de água e o ponto máximo em matéria seca. Dependendo da época e da dose em que o dessecante é aplicado, a qualidade das sementes e a produtividade podem ser afetadas (Kappes et al., 2009). Portanto, o conhecimento desses fatores torna-se de extrema importância para se evitarem eventuais perdas de produtividade da cultura.

Com base no exposto, o objetivo deste trabalho foi avaliar a produtividade de feijoeiro de inverno, após aplicação do dessecante paraquat, em diferentes épocas e doses do produto em pré-colheita da cultura.

\section{MATERIAL E MÉTODOS}

O feijão foi cultivado no período de outono/inverno de 2010, no município de Selvíria, Mato Grosso do Sul, em área experimental da Universidade Estadual Paulista $\left(20^{\circ}\right.$ $20^{\prime}$ S e $51^{\circ} 24^{\prime}$ W), com altitude de $340 \mathrm{~m}$. O clima da região, segundo classificação de Köppen, é do tipo Aw, com precipitação pluvial média anual de $1.330 \mathrm{~mm}$, temperatura do ar média anual de $25{ }^{\circ} \mathrm{C}$ e umidade relativa do ar média anual de $66 \%$. Os dados de umidade relativa do ar e de temperatura mínima e máxima do ar registrados, por decêndio, durante o ciclo da cultura, podem ser observados na Figura 1.

O solo da área experimental é classificado como Latossolo Vermelho distrófico álico (Embrapa, 2006), com textura argilosa, cuja análise química, realizada na camada de 0 a 0,2 m, revelou os seguintes valores: MO: $28 \mathrm{~g} \mathrm{dm}^{-3}$; $\mathrm{pH}\left(\mathrm{CaCl}_{2}\right): 5,4$; P (resina); S, B, Cu, Fe, Mn e Zn: 15; 1 ; 0,$25 ; 2,9 ; 22 ; 26,6$ e $0,6 \mathrm{mg} \mathrm{dm}^{-3}$, respectivamente; $\mathrm{K}, \mathrm{Ca}$, 
$\mathrm{Mg}, \mathrm{H}+\mathrm{Al} \mathrm{e} \mathrm{CTC}: 3,4 ; 24 ; 15 ; 25$ e $67,4 \mathrm{mmol}_{\mathrm{c}} \mathrm{dm}^{-3}$, respectivamente; e V: $63 \%$.

O experimento foi instalado em área anteriormente cultivada com arroz de terras altas, em esquema de sucessão de culturas (arroz, feijão e arroz - cultura antecessora), em sistema convencional de manejo do solo, utilizando-se aração e gradagem de nivelamento. O cultivar utilizado foi o Carioca Precoce, de hábito de crescimento determinado (tipo I). As sementes foram tratadas com fungicida carboxina + tiram $(60+60 \mathrm{~g}$ para $100 \mathrm{~kg}$ de sementes $)$ e a semeadura mecanizada realizada em $07 / 05 / 2010$, distribuindo-se 12 sementes por metro a uma profundidade de 4,0 $\mathrm{cm}$, em espaçamento de $0,45 \mathrm{~m}$ entre as linhas. A emergência das plântulas ocorreu aos seis dias após a semeadura, estabelecendo-se população de 215.000 plantas ha $^{-1}$.

$\mathrm{Na}$ adubação mineral de semeadura, foram aplicados $260 \mathrm{~kg} \mathrm{ha}^{-1}$ da fórmula 08-28-16 (+1\% de Ca; $2 \%$ de S e 0,3\% de Zn). Aos 20 dias após a emergência das plântulas, momento em que $50 \%$ das plantas apresentavam-se com a terceira folha trifoliolada completamente aberta, estádio fenológico $\mathrm{V}_{3-4}$ (Fernández et al., 1992), foi realizada a adubação nitrogenada de cobertura, com $80 \mathrm{~kg} \mathrm{ha}^{-1} \mathrm{de}$ $\mathrm{N}$, com a fonte sulfato de amônio (20\% de N + 24\% de S), de acordo com recomendações de Ambrosano et al. (1996). O fertilizante foi aplicado de forma manual e em superfície, sem incorporação. Em seguida, a área foi irrigada, sendo o fornecimento de água realizado por meio de sistema fixo de irrigação por aspersão. No manejo de água, foram utilizados valores de Kc (coeficiente de cultura) semelhantes aos recomendados por Doorenbos \& Kassam (1979), ou seja, para as fases de $V_{0}-V_{1}$ (Kc: 0,30), de $V_{3}-V_{4}(K c: 0,70)$, de $R_{5}-R_{7}(K c: 1,05), R_{8}(K c:$ $0,75)$ e $\mathrm{R}_{9}$ (Kc: 0,25).

As plantas daninhas foram controladas em pós-emergência, utilizando-se os herbicidas fluazifop-p-butil + fomesafen $\left(120+150 \mathrm{~g} \mathrm{ha}^{-1}\right)$. A aplicação foi realizada

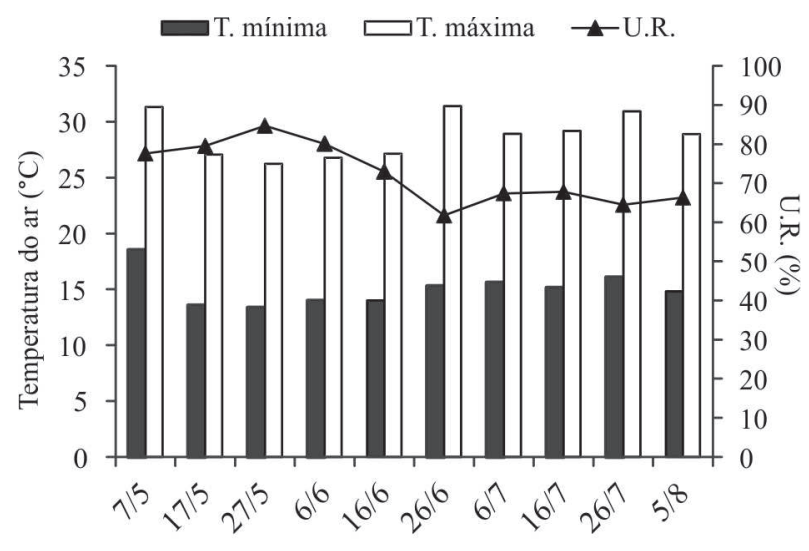

Decêndios observados (2010)

Figura 1. Temperatura mínima e máxima do ar e umidade relativa do ar (U.R.), por decêndio, registradas durante a condução do experimento, no município de Selvíria, Mato Grosso do Sul, Brasil. quando a cultura encontrava-se no estádio de desenvolvimento $\mathrm{V}_{3-4}$ e as plantas daninhas em estádios de plântulas. $\mathrm{O}$ controle dos principais insetos praga e das doenças foi realizado por meio de pulverizações com produtos registrados para a cultura e específicos para cada caso. As aplicações foram realizadas com pulverizador costal manual com capacidade de pressão de trabalho de $6,0 \mathrm{kgf} \mathrm{cm}^{-2}$, munido com ponta de jato cone vazio e volume de calda aproximado de $200 \mathrm{~L} \mathrm{ha}^{-1}$. O florescimento ocorreu aos 35 dias após a emergência das plântulas.

Foram avaliados dezesseis tratamentos, dispostos em esquema fatorial $4 \times 4$ (épocas $\mathrm{x}$ doses de aplicação de dessecante), com quatro repetições, utilizando-se delineamento em blocos ao acaso. As parcelas foram constituídas por seis linhas de 5,0 $\mathrm{m}$ de comprimento, espaçadas de $0,45 \mathrm{~m}$ entre si, perfazendo área total de $13,5 \mathrm{~m}^{2}$ e área útil de $9,0 \mathrm{~m}^{2}$, representada pelas quatro linhas centrais, sendo que na determinação de produtividade foram colhidas as duas linhas centrais de cada parcela $\left(4,5 \mathrm{~m}^{2}\right)$.

O dessecante utilizado foi o paraquat (1,1'-dimetil4,4-bipiridilio dicloreto, íon) nas seguintes doses: 0,0 (testemunha); 200; 400 e $600 \mathrm{~g} \mathrm{ha}^{-1}$, correspondentes a $0 ; 1 ; 2$ e $3 \mathrm{~L} \mathrm{ha}^{-1}$ do produto comercial Gramaxone ${ }^{\circledR}$. As aplicações foram realizadas a partir do estádio $\mathrm{R}_{9}$, aos $30,35,40$ e 45 dias após o florescimento (DAF), momento em que as sementes apresentavam-se com teor médio de água de $620,590,550 \mathrm{e} 300 \mathrm{~g} \mathrm{~kg}^{-1}$. A determinação do teor de água das sementes foi realizada pelo método da estufa a $105^{\circ} \mathrm{C}$ $\pm 3{ }^{\circ} \mathrm{C}$, durante 24 horas (Brasil, 2009). O dessecante foi aplicado, à pressão constante de $3,0 \mathrm{kgf} \mathrm{cm}^{-2}$, com pulverizador costal pressurizado por $\mathrm{CO}_{2}$, munido de barra com pontas jato cone vazio TXA 8002 VK. As aplicações foram realizadas sempre no período da tarde, utilizando-se o volume aproximado de calda de $250 \mathrm{~L} \mathrm{ha}^{-1}$.

Além da determinação da população final de plantas, na ocasião da colheita, foram retiradas 10 plantas da área útil de cada parcela, para mensuração do número de vagens por planta e número de sementes por vagem e por planta. Após a trilhagem das vagens, determinou-se: a) percentual de sementes defeituosas: obtido pela coleta de duas subamostras de 100 sementes por parcela, conforme metodologia utilizada por Kappes et al. (2008), computando-se as sementes que apresentavam algum tipo de deformação; b) tamanho de sementes: as sementes foram classificadas em peneiras de crivo redondo, sendo "pequenas" as que passaram pela peneira de largura 16/30" (peneira 15) e ficaram retidas em peneira de largura 14/30" (peneira 13); "médias", as que passaram pela peneira de largura 19/30" (peneira 17) e ficaram retidas na peneira 15; e "graúdas", as que ficaram retidas na peneira 17 ; c) massa de mil sementes: pesagem de uma subamostra de 250 sementes por parcela em balança de precisão $(0,01 \mathrm{~g})$ e correção de sua massa para $130 \mathrm{~g} \mathrm{~kg}^{-1}$ (base úmida - "b.u."), com os resultados 
extrapolados para mil sementes; d) produtividade: obtida pelo peso das sementes oriundas da área útil, corrigido para $130 \mathrm{~g} \mathrm{~kg}^{-1}$ (b.u.) e extrapolado para $\mathrm{kg} \mathrm{ha}^{-1}$.

Observações do ciclo da cultura e do teor de água das sementes foram realizadas por ocasião da colheita, a qual foi realizada manualmente, no momento em que a maioria das plantas apresentava-se com as vagens secas (ponto de maturação de colheita), correspondendo, nas sementes, ao teor de água de $145 \pm 7 \mathrm{~g} \mathrm{~kg}^{-1}$. O teor de água foi obtido pelo método elétrico não destrutivo indireto, mediante o uso do aparelho portátil Multi-grain, modelo Dickey-John ${ }^{\circledR}$.

Os resultados foram submetidos à análise de variância, pelo software SISVAR ${ }^{\circledR}$, e os efeitos de épocas de aplicação foram comparados pelo teste de Tukey, a 5\% de probabilidade, de acordo com Pimentel Gomes \& Garcia (2002) e os efeitos de doses por análise de regressão polinomial.

\section{RESULTADOS E DISCUSSÃO}

Apesar da constatação de amplitude de 13,4 e 31,4 ${ }^{\circ} \mathrm{C}$, entre as temperaturas mínima e a máxima, respectivamente (Figura 1), este fator ambiental não foi limitante ao adequado desenvolvimento da cultura, neste estudo, haja vista que o feijoeiro é cultivado sob temperaturas variando de 10 a $35^{\circ} \mathrm{C}$ (Silva \& Didonet, 2005).

Tal como era esperado, a aplicação de paraquat em pré-colheita não afetou o número de vagens por planta, o de sementes por vagem, o de sementes por planta e a população final de plantas (Tabela 1), fato este justificado por que, na ocasião das aplicações, estes caracteres já se encontravam definidos, passando a sofrer inexpressivas influências do dessecante. Portanto, a não constatação de diferenças significativas demonstra a homogeneidade da cultura na área experimental, podendo-se inferir que as respostas dos demais caracteres à aplicação de paraquat não foram prejudicadas pelo número de vagens por planta, sementes por vagem, sementes por planta e população final de plantas.

O percentual de sementes defeituosas foi influenciado pela interação entre épocas e doses de aplicação de paraquat em pré-colheita (Tabela 1). Comparando-se as épocas de aplicação dentro de cada dose, constata-se que as médias de percentuais de sementes defeituosas apresentaram o mesmo comportamento em todas as doses, exceto na testemunha (Tabela 3). A aplicação de paraquat aos 30 DAF resultou em maior percentual de sementes defeituosas, sendo que, a partir dos $35 \mathrm{DAF}$, não foram constatadas diferença entre as épocas. Diferentemente do constatado neste estudo, Lacerda et al. (2005) constataram, no ano agrícola de 1997/1998, que a aplicação de paraquat (400 $\left.\mathrm{g} \mathrm{ha}^{-1}\right)$, diquat $\left(300 \mathrm{~g} \mathrm{ha}^{-1}\right)$, mistura de paraquat + diquat $\left(200+150 \mathrm{~g} \mathrm{ha}^{-1}\right) \mathrm{e}$ glufosinato de amônio (400 $\mathrm{g} \mathrm{ha}^{-1}$ ), com intervalo entre elas de cinco dias, após o início do estádio $\mathrm{R}_{6}$ (pleno enchimento das vagens), até o estádio $\mathrm{R}_{7}$ (início da maturação) da cultura da soja em Selvíria - MS, e não observaram

Tabela 1. Valores de F e médias de número de vagens por planta (VP), sementes por vagem (SV), sementes por planta (SP), população final de plantas (PFP) e percentual de sementes defeituosas (SD) de feijoeiro de inverno em função de épocas e doses de aplicação de paraquat

\begin{tabular}{|c|c|c|c|c|c|}
\hline \multirow[t]{2}{*}{ Tratamentos } & VP & SV & SP & PFP & SD \\
\hline & \multicolumn{3}{|c|}{$n^{0}$} & $\left(\right.$ plantas ha $\left.{ }^{-1}\right)$ & $\%$ \\
\hline \multicolumn{6}{|l|}{ Épocas-E } \\
\hline $30 \mathrm{DAF}$ & 12,6 & 4,2 & 52,5 & 209.444 & 8,9 \\
\hline $35 \mathrm{DAF}$ & 12,5 & 4,0 & 50,6 & 197.528 & 3,4 \\
\hline $40 \mathrm{DAF}$ & 13,8 & 4,3 & 59,3 & 192.083 & 3,3 \\
\hline $45 \mathrm{DAF}$ & 13,4 & 4,2 & 56,7 & 192.222 & 2,5 \\
\hline Teste F & $0,91^{\mathrm{NS}}$ & $2,03^{\mathrm{NS}}$ & $1,48^{\mathrm{NS}}$ & $3,72^{\mathrm{NS}}$ & $37,71 * *$ \\
\hline \multicolumn{6}{|l|}{ Doses - D } \\
\hline $0 \mathrm{~g} \mathrm{ha}^{-1}$ & 12,8 & 4,2 & 53,7 & 186.667 & 1,9 \\
\hline $200 \mathrm{~g} \mathrm{ha}^{-1}$ & 12,8 & 4,2 & 54,1 & 194.305 & 4,7 \\
\hline $400 \mathrm{~g} \mathrm{ha}^{-1}$ & 13,4 & 4,0 & 55,1 & 197.917 & 5,7 \\
\hline $600 \mathrm{~g} \mathrm{ha}^{-1}$ & 13,3 & 4,2 & 56,4 & 196.389 & 5,6 \\
\hline Teste F & $0,22^{\mathrm{NS}}$ & $0,59^{\mathrm{NS}}$ & $0,14^{\mathrm{NS}}$ & $0,69^{\mathrm{NS}}$ & $14,12 * *$ \\
\hline \multicolumn{6}{|c|}{ Interação E x D } \\
\hline Teste $\mathrm{F}$ & $0,79^{\mathrm{NS}}$ & $0,59^{\mathrm{NS}}$ & $0,70^{\mathrm{NS}}$ & $0,43^{\mathrm{NS}}$ & $4,41 * *$ \\
\hline Média geral & 13,1 & 4,1 & 54,8 & 195.819 & 4,5 \\
\hline $\mathrm{CV}(\%)$ & 21,02 & 7,82 & 23,68 & 12,37 & 42,36 \\
\hline
\end{tabular}

** e NS - significativo a $1 \%$ de probabilidade e não significativo pelo teste $\mathrm{F}$, respectivamente; DAF - dias após o florescimento; CV coeficiente de variação. 
efeitos dos tratamentos na percentagem de sementes defeituosas. O fato de a aplicação de paraquat aos $30 \mathrm{DAF}$ ter proporcionado maior percentual de sementes defeituosas pode estar relacionado ao alto teor de água nas sementes $\left(620 \mathrm{~g} \mathrm{~kg}^{-1}\right)$, nesta ocasião, e, certamente, imaturas fisiologicamente. Desse modo, a rápida desidratação das sementes, a partir da aplicação do dessecante na referida época, fez com que estas se tornassem defeituosas.

$\mathrm{O}$ incremento das doses de paraquat provocou aumento linear do percentual de sementes defeituosas aos 30 e 35 DAF (Figura 2a), ao contrário das testemunhas, que apresentaram os menores percentuais de sementes com defeitos no tegumento. Kappes et al. (2008), estudando os efeitos de épocas de aplicações $\left(\mathrm{R}_{6.0}, \mathrm{R}_{7.1}, \mathrm{R}_{7.2} \mathrm{e}\right.$ $\mathrm{R}_{7.3}$ ) dos dessecantes diquat e paraquat (400 $\left.\mathrm{g} \mathrm{ha}^{-1}\right)$, na pré-colheita da cultura da soja, constataram interação significativa entre os fatores testados, sendo que as testemunhas apresentaram menores percentuais de sementes defeituosas, em todas as épocas avaliadas, exceto na última época $\left(\mathrm{R}_{7.3}\right)$, condizente com o evidenciado neste estudo com a cultura do feijoeiro. Por outro lado, as aplicações realizadas aos 40 e 45 DAF não tiveram suas médias ajustadas por equações de regressões.

A massa de mil sementes apresentou resposta similar à do percentual de sementes defeituosas e foi influenciada pela interação entre épocas e doses de paraquat (Tabela 2). O paraquat aplicado aos 30 DAF afetou a massa das sementes em todas as doses testadas, com exceção para o tratamento testemunha (Tabela 3). Nota-se considerável aumento na massa de mil sementes, à medida que a cultura foi dessecada mais tardiamente, fato justificado pelo acúmulo gradativo de matéria seca nas sementes. Tais resultados não corroboram os de Domingos et al. (2001), ao verificarem que a aplicação de paraquat (400 g $\left.\mathrm{ha}^{-1}\right)$ e mistura de paraquat + diquat $\left(250+150 \mathrm{~g} \mathrm{ha}^{-1}\right)$, aos 37, 41 e 45 DAF, não afetaram a massa de cem sementes de feijão. Inoue et al. (2003) aplicaram diquat (300 g $\left.\mathrm{ha}^{-1}\right)$, paraquat $\left(400 \mathrm{~g} \mathrm{ha}^{-1}\right)$, glufosinato de amônio (500 $\mathrm{g}$ $\left.\mathrm{ha}^{-1}\right)$ e carfentrazone-ethyl (30 $\left.\mathrm{g} \mathrm{ha}^{-1}\right)$, quando a cultura da soja encontrava-se no estádio $\mathrm{R}_{7.5}(50 \%$ das vagens com a cor de vagem madura) e não observaram diferença significativa entre os resultados dos tratamento com os dessecantes e os da testemunha, para a massa de cem sementes.

$\mathrm{Na}$ análise de regressão, observa-se que o incremento das doses de paraquat afetou linearmente a massa de mil sementes, até os 40 DAF (Figura 2b). Santos et al. (2004) avaliaram a dessecação em feijoeiro com carfentrazoneethyl e constataram que as sementes colhidas ao final da primeira época de dessecação (25 DAF) apresentaram redução da massa com o aumento da dose do dessecante. Neste estudo, as maiores massas de sementes foram observadas nos tratamentos que não receberam dessecação, corroborando os resultados obtidos por Kappes et al. (2008), ao verificarem que a massa de cem sementes de soja foi maior nas testemunhas, em relação aos tratamen-

Tabela 2. Valores de F e médias de massa de mil sementes (MMS), tamanho de sementes e produtividade (PROD) de feijoeiro de inverno em função de épocas e doses de aplicação de paraquat

\begin{tabular}{|c|c|c|c|c|c|}
\hline \multirow[t]{2}{*}{ Tratamentos } & \multirow{2}{*}{$\begin{array}{r}\mathbf{M M S}^{(1)} \\
\mathbf{g}\end{array}$} & \multicolumn{3}{|c|}{ Tamanho de sementes $(\%)$} & \multirow{2}{*}{$\begin{array}{c}\text { PROD }^{(1)} \\
\left(\mathrm{kg} \mathrm{ha}^{-1}\right)\end{array}$} \\
\hline & & pequenas & médias & graúdas & \\
\hline \multicolumn{6}{|l|}{ Épocas-E } \\
\hline $30 \mathrm{DAF}$ & 192,1 & 12,5 & 72,6 & 14,9 & $1.716 \mathrm{~b}$ \\
\hline $35 \mathrm{DAF}$ & 227,7 & 6,7 & 68,2 & 25,1 & $2.034 \mathrm{a}$ \\
\hline $40 \mathrm{DAF}$ & 232,0 & 6,0 & 71,4 & 22,6 & $2.123 \mathrm{a}$ \\
\hline $45 \mathrm{DAF}$ & 248,1 & 6,0 & 70,0 & 24,0 & $2.246 \mathrm{a}$ \\
\hline Teste F & $81,67 * *$ & $65,31 * *$ & $4,97 *$ & $25,66 * *$ & $15,81 * *$ \\
\hline \multicolumn{6}{|l|}{ Doses - D } \\
\hline $0 \mathrm{~g} \mathrm{ha}^{-1}$ & 249,5 & 4,6 & 66,1 & 29,3 & 2.260 \\
\hline $200 \mathrm{~g} \mathrm{ha}^{-1}$ & 227,3 & 7,1 & 71,0 & 21,9 & 2.040 \\
\hline $400 \mathrm{~g} \mathrm{ha}^{-1}$ & 214,3 & 9,5 & 72,0 & 18,5 & 1.973 \\
\hline $600 \mathrm{~g} \mathrm{ha}^{-1}$ & 208,8 & 9,8 & 73,3 & 16,9 & 1.846 \\
\hline Teste F & $48,13 * *$ & $39,04 * *$ & $13,74 * *$ & $36,84 * *$ & $9,26 * *$ \\
\hline \multicolumn{6}{|c|}{ Interação E x D } \\
\hline Teste F & $7,42 * *$ & $12,65 * *$ & $3,07 *$ & $3,99 * *$ & $1,55^{\mathrm{NS}}$ \\
\hline Média geral & 225,0 & 7,8 & 70,6 & 21,6 & 2.030 \\
\hline $\mathrm{CV}(\%)$ & 4,64 & 14,07 & 3,43 & 11,92 & 11,22 \\
\hline
\end{tabular}

Rev. Ceres, Viçosa, v. 59, n.1, p. 56-64, jan/fev, 2012 
tos que receberam aplicação de diquat e paraquat em pré-colheita. A redução da massa de sementes com a elevação das doses de paraquat, observada aos 30, 35 e 40 DAF, pode ser atribuída à rápida perda de água das sementes, resultante da ação do dessecante. Possivelmente, a perda acelerada de água prejudicou o desvio de fotoassimilados para as sementes, proporcionando desigualdade no seu enchimento, principalmente na primeira época de aplicação, quando o teor de água era superior a $600 \mathrm{~g} \mathrm{~kg}^{-1}$ da massa total das sementes, conforme também evidenciado por Santos et al. (2004). Essa hipótese é reforçada quando se observa que, para as plantas dessecadas aos 45 DAF, não se observou ajuste de análise de regressão para os valores médios de massa de mil sementes (Figura 2b).

No que diz respeito ao tamanho de sementes, observa-se efeito de interação entre épocas e doses de paraquat (Tabela 2). Exceto para a testemunha, maior percentual de sementes pequenas foi constatado nos tratamentos com

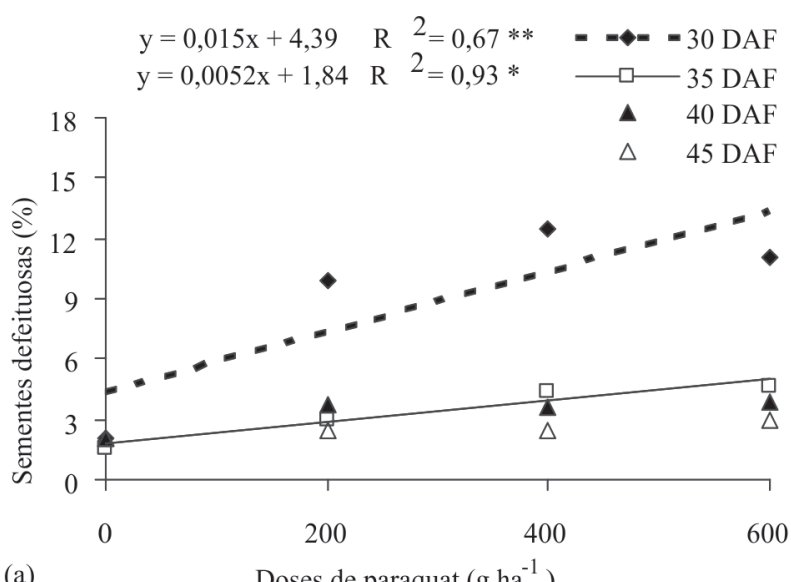

(a)

Doses de paraquat $\left(\mathrm{g} \mathrm{ha}^{-1}\right)$

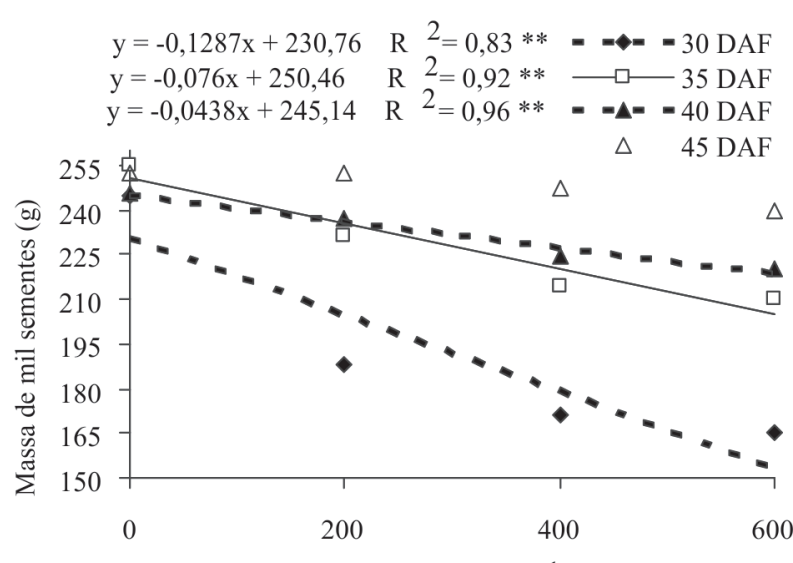

(b) Doses de paraquat $\left(\mathrm{g} \mathrm{ha}^{-1}\right)$

Figura 2. Percentual de sementes defeituosas (a) e massa de mil sementes (b) de feijoeiro de inverno em função de épocas e doses de aplicação de paraquat. ** e * significativo a 1 e $5 \%$ de probabilidade pelo teste $\mathrm{F}$, respectivamente; DAF - dias após o florescimento. dessecação realizada aos $30 \mathrm{DAF}$ (Tabela 4). O percentual de sementes médias não foi afetado pelas épocas de aplicações de 200 e $600 \mathrm{~g} \mathrm{ha}^{-1}$ de paraquat, enquanto a dessecação aos 45 DAF proporcionou a obtenção de menor percentual de sementes médias, com a aplicação de $400 \mathrm{~g} \mathrm{ha}^{-1}$ de paraquat, apesar de não se haver consta-
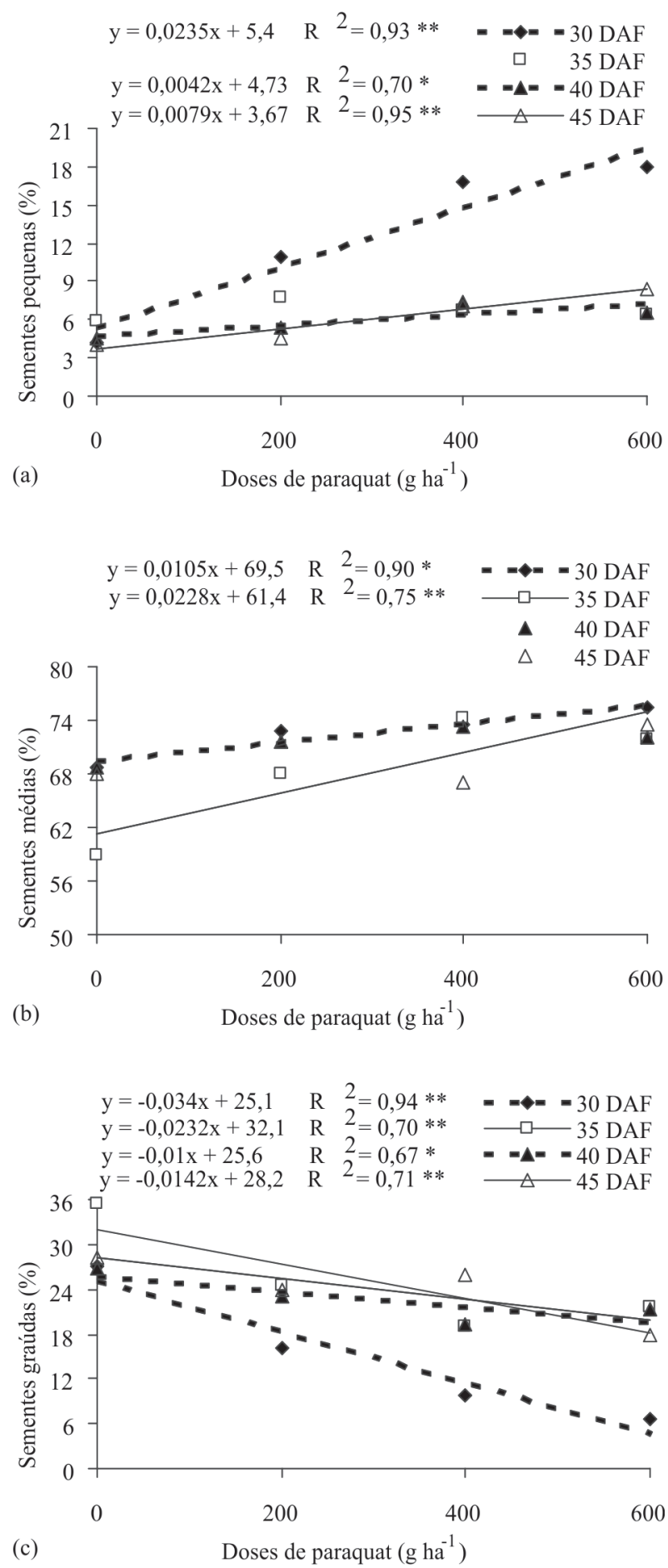

Figura 3. Percentual de sementes pequenas (a), médias (b) e graúdas (c) de feijoeiro de inverno em função de épocas e doses de aplicação de paraquat. $* *$ e $*$ significativo a 1 e $5 \%$ de probabilidade pelo teste $\mathrm{F}$, respectivamente; DAF - dias após o florescimento. 
tado diferença com a aplicação aos 30 e 40 DAF. Em todas as doses testadas, menor percentual de sementes graúdas foi verificado aos $30 \mathrm{DAF}$, em detrimento do maior percentual de sementes pequenas, verificado nessa ocasião, confirmando novamente que a perda acelerada de água prejudicou o desvio de fotoassimilados para as sementes e, consequentemente, desigualdade no seu enchimento.

Para as dessecações realizadas aos 30, 40 e 45 DAF, ocorreu aumento linear no percentual de sementes pequenas, com o incremento das doses de paraquat (Figura 3a). Na dessecação realizada aos $35 \mathrm{DAF}$, não houve ajuste de equação significativa para as médias. O percentual de sementes médias aumentou linearmente, à medida que se aumentaram as doses de paraquat, aos 30 e 35 DAF (Figura 3b). Nas dessecações realizadas aos 40 e 45 DAF, não houve ajuste de equação significativa para as médias. Por sua vez, o percentual de sementes graúdas diminuiu linearmente em todas as épocas de aplicações (Figura 3c), evidenciando efeito tóxico do paraquat, principalmente, na dose de $600 \mathrm{~g} \mathrm{ha}^{-1}$. De fato, evidenciou-se que, em média, 70,6\% das sementes foram classificadas como médias, ao passo que 7,8 e 21,6\% foram classificadas como pequenas e graúdas, respectivamente (Tabela 2). De modo semelhante, Santos et al. (2004) obtiveram percentuais de 6,4, 63,7 e 29,9\% de sementes menores, médias e maiores, respectivamente, após a aplicação de carfentrazone-ethyl aos $30 \mathrm{DAF}$.

Tabela 3. Desdobramento da interação entre épocas e doses de aplicação de paraquat em feijoeiro de inverno para percentual de sementes defeituosas e massa de mil sementes

\begin{tabular}{|c|c|c|c|c|}
\hline \multirow[t]{2}{*}{ Época de aplicação } & \multicolumn{4}{|c|}{ Doses de paraquat ( $\mathrm{g} \mathrm{ha}^{-1}$ ) } \\
\hline & $\mathbf{0}$ & 200 & 400 & 600 \\
\hline \multicolumn{5}{|c|}{ Sementes defeituosas $(\%)$} \\
\hline $30 \mathrm{DAF}$ & $2,0 \mathrm{a}$ & $9,9 \mathrm{a}$ & $12,5 \mathrm{a}$ & $11,1 \mathrm{a}$ \\
\hline $35 \mathrm{DAF}$ & $1,6 \mathrm{a}$ & $3,0 \mathrm{~b}$ & $4,4 \mathrm{~b}$ & $4,6 \mathrm{~b}$ \\
\hline $40 \mathrm{DAF}$ & $2,0 \mathrm{a}$ & $3,7 \mathrm{~b}$ & $3,6 \mathrm{~b}$ & $3,9 \mathrm{~b}$ \\
\hline $45 \mathrm{DAF}$ & $2,0 \mathrm{a}$ & $2,4 \mathrm{~b}$ & $2,5 \mathrm{~b}$ & $3,0 \mathrm{~b}$ \\
\hline \multicolumn{5}{|c|}{ Massa de mil sementes $(\mathrm{g})^{1}$} \\
\hline $30 \mathrm{DAF}$ & $245,0 \mathrm{a}$ & $187,9 \mathrm{c}$ & $170,8 \mathrm{c}$ & $164,9 \mathrm{c}$ \\
\hline $35 \mathrm{DAF}$ & $255,0 \mathrm{a}$ & $231,3 \mathrm{~b}$ & $214,4 \mathrm{~b}$ & $210,0 \mathrm{~b}$ \\
\hline $40 \mathrm{DAF}$ & $245,5 \mathrm{a}$ & $237,4 \mathrm{ab}$ & $224,5 \mathrm{~b}$ & $220,6 \mathrm{ab}$ \\
\hline $45 \mathrm{DAF}$ & $252,8 \mathrm{a}$ & $252,7 \mathrm{a}$ & $247,4 \mathrm{a}$ & $239,7 \mathrm{a}$ \\
\hline
\end{tabular}

Médias, seguidas por mesma letra nas colunas, não diferem pelo teste de Tukey a 5\% de probabilidade; DAF - dias após o florescimento;

${ }^{1}$ Com base em $130 \mathrm{~g} \mathrm{~kg}^{-1}$ de teor de água das sementes.

Tabela 4. Desdobramento da interação entre épocas e doses de aplicação de paraquat em feijoeiro de inverno para tamanho de sementes

\begin{tabular}{|c|c|c|c|c|}
\hline \multirow[t]{2}{*}{ Época de aplicação } & \multicolumn{4}{|c|}{ Doses de paraquat $\left(\mathrm{g} \mathrm{ha}^{-1}\right)$} \\
\hline & $\mathbf{0}$ & 200 & 400 & 600 \\
\hline \multicolumn{5}{|c|}{ Sementes pequenas $(\%)$} \\
\hline $30 \mathrm{DAF}$ & $4,2 \mathrm{a}$ & $10,9 \mathrm{a}$ & $16,8 \mathrm{a}$ & $17,9 \mathrm{a}$ \\
\hline $35 \mathrm{DAF}$ & $5,8 \mathrm{a}$ & $7,7 \mathrm{~b}$ & $6,7 b$ & $6,4 \mathrm{~b}$ \\
\hline $40 \mathrm{DAF}$ & $4,5 \mathrm{a}$ & $5,4 \mathrm{bc}$ & $7,4 \mathrm{~b}$ & $6,6 \mathrm{~b}$ \\
\hline $45 \mathrm{DAF}$ & $4,0 \mathrm{a}$ & $4,6 \mathrm{c}$ & $7,1 \mathrm{~b}$ & $8,4 \mathrm{~b}$ \\
\hline \multicolumn{5}{|c|}{ Sementes médias (\%) } \\
\hline $30 \mathrm{DAF}$ & $68,7 \mathrm{a}$ & $72,9 \mathrm{a}$ & $73,5 \mathrm{ab}$ & $75,5 \mathrm{a}$ \\
\hline $35 \mathrm{DAF}$ & $58,8 \mathrm{~b}$ & $67,9 \mathrm{a}$ & $74,2 \mathrm{a}$ & $71,9 \mathrm{a}$ \\
\hline $40 \mathrm{DAF}$ & $68,7 \mathrm{a}$ & $71,7 \mathrm{a}$ & $73,2 \mathrm{ab}$ & $72,1 \mathrm{a}$ \\
\hline $45 \mathrm{DAF}$ & $67,9 \mathrm{a}$ & $71,5 \mathrm{a}$ & $67,0 \mathrm{~b}$ & $73,6 \mathrm{a}$ \\
\hline \multicolumn{5}{|c|}{ Sementes graúdas (\%) } \\
\hline $30 \mathrm{DAF}$ & $27,1 \mathrm{~b}$ & $16,2 \mathrm{~b}$ & $9,7 \mathrm{~b}$ & $6,6 \mathrm{~b}$ \\
\hline $35 \mathrm{DAF}$ & $35,4 \mathrm{a}$ & $24,4 \mathrm{a}$ & $19,1 \mathrm{a}$ & $21,7 \mathrm{a}$ \\
\hline $40 \mathrm{DAF}$ & $26,8 \mathrm{~b}$ & $22,9 \mathrm{ab}$ & $19,4 \mathrm{a}$ & $21,3 \mathrm{a}$ \\
\hline $45 \mathrm{DAF}$ & $28,1 \mathrm{ab}$ & $23,9 \mathrm{a}$ & $25,9 \mathrm{a}$ & $18,0 \mathrm{a}$ \\
\hline
\end{tabular}

Médias, seguidas por mesma letra nas colunas, não diferem pelo teste de Tukey a 5\% de probabilidade; DAF - dias após o florescimento.

Rev. Ceres, Viçosa, v. 59, n.1, p. 56-64, jan/fev, 2012 
A produtividade do feijoeiro foi influenciada, de modo independente, pelas épocas e doses de paraquat (Tabela 2). A dessecação efetuada aos $30 \mathrm{DAF}$ reduziu a produtividade, sendo que, a partir desse estádio, não foi mais constatada redução de produtividade pelo paraquat. Miguel (2003) verificou que, para o paraquat aplicado a partir dos 32 DAF do feijoeiro, as produtividades foram semelhantes às da testemunha. Esses resultados demonstram a importância da correta identificação do estádio de desenvolvimento da cultura e que, para o feijoeiro, cultivar Carioca Precoce, quando se optar pela técnica da dessecação, esta deverá ser realizada, respeitando-se um intervalo mínimo de 35 dias entre o início de florescimento e a aplicação do dessecante. Provavelmente, quando a aplicação foi realizada aos $30 \mathrm{DAF}$, as sementes não apresentavam o seu máximo acúmulo de biomassa seca, ou seja, encontravam-se fisiologicamente imaturas. Teófilo et al. (1996) concluíram que a aplicação de paraquat em pré-colheita do feijoeiro, antes do ponto de maturidade fisiológica, resulta na obtenção de sementes menores e produtividade inferior, assim como a aplicação de $400 \mathrm{~g}$ ha $^{-1}$ de paraquat aos 50 DAF foi eficiente na dessecação da cultura, proporcionando maior tamanho de sementes, máxima produtividade e antecipação da colheita em quatro dias. Silva et al. (1999) e Miguel (2003) observaram aumento de produtividade do feijoeiro à medida que se retardaram as aplicações de dessecantes em pré-colheita, ao contrário de Domingos et al. (2001), os quais não constataram redução de produtividade do feijoeiro, após a dessecação em pré-colheita.

$\mathrm{O}$ aumento das doses do paraquat provocou redução linear da produtividade (Figura 4), podendo-se inferir que, para cada aumento de $100 \mathrm{~g} \mathrm{ha}^{-1}$, houve redução de 65,4 $\mathrm{kg} \mathrm{ha}^{-1}$ na produtividade da cultura. Maiores produtividades foram obtidas na ausência do dessecante e isso aconteceu porque as plantas não dessecadas tiveram mais tem- po para atingirem o ponto de maturidade fisiológica, acumulando o máximo possível em fotossintetizados e, em consequência, adquiriram acréscimos em sua massa seca. Já Inoue et al. (2003) não observaram diferença, entre os tratamentos que envolveram dessecação, na presença de $50 \%$ das vagens com a cor de vagem madura, e a testemunha para a produtividade da cultura da soja.

Embora se trate de cultivo irrigado, a produtividade média obtida foi considerada baixa $\left(2.030 \mathrm{~kg} \mathrm{ha}^{-1}\right)$, aquém do potencial genético que a cultura apresenta nesse sistema de cultivo. Por outro lado, a produtividade constatada foi superior à média nacional e à do Estado de Mato Grosso do Sul, obtida no cultivo de terceira safra (safra de outono/inverno), no ano agrícola de 2008/2009, que foi de apenas 1.010 e $1.333 \mathrm{~kg} \mathrm{ha}^{-1}$, respectivamente (Conab, 2010).

Admitindo-se que, na ausência de dessecação, a colheita ocorreu aos 85 dias após a semeadura (50 DAF), pode-se inferir que a utilização de paraquat como dessecante aos 30 DAF pode antecipar a colheita do feijão em até sete dias, com teor de água das sementes em torno de $140 \mathrm{~g} \mathrm{~kg}^{-1}$ (Figura 5). Contudo, esta antecipação do ciclo da cultura foi acompanhada pela redução de $24 \%$ na produtividade, em comparação com a da testemunha (Tabela 2). Santos et al. (2004) obtiveram antecipação do ciclo em sete dias com a aplicação de carfentrazoneethyl em feijoeiro, sem interferência na produtividade. Domingos et al. (1997) observaram que a aplicação de paraquat $\left(400 \mathrm{~g} \mathrm{ha}^{-1}\right)$, mistura de paraquat + diquat $\left(250+150 \mathrm{~g} \mathrm{ha}^{-1}\right)$ e glufosinato de amônio $\left(400 \mathrm{~g} \mathrm{ha}^{-1}\right)$, aos 26 e 29 DAF, antecipou a colheita do cultivar Carioca entre treze e sete dias, respectivamente. Concordando com os resultados destes autores, Marchiori Júnior et al. (2002) observaram que a dessecação com carfentrazone-ethyl (30 $\mathrm{g} \mathrm{ha}^{-1}$ ) antecipou a colheita de canola em sete dias e não interferiu com a produtividade da cultura.

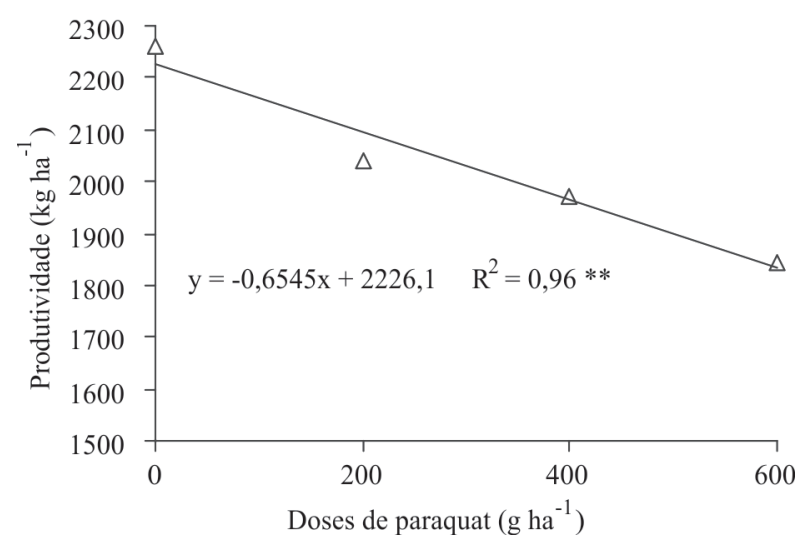

Figura 4. Produtividade de feijoeiro de inverno em função de doses de aplicação de paraquat. $* *$ significativo a $1 \%$ de probabilidade pelo teste $\mathrm{F}$.

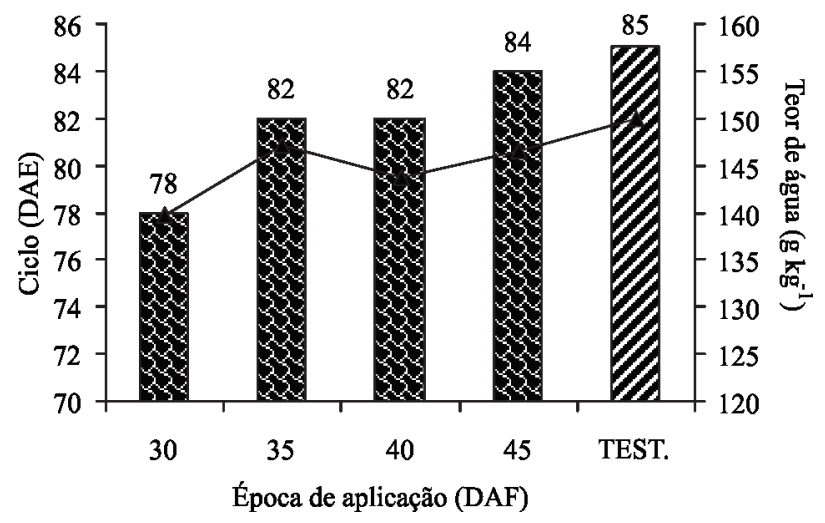

Figura 5. Ciclo da cultura e teor de água das sementes, na ocasião da colheita, em função de épocas e doses de aplicação de paraquat em feijoeiro de inverno. DAE - dias após a emergência; DAF dias após o florescimento; TEST. - testemunha.

Rev. Ceres, Viçosa, v. 59, n.1, p. 56-64, jan/fev, 2012 
As aplicações de paraquat aos 35, 40 e 45 DAF não reduziram significativamente a produtividade do feijoeiro, cultivar Carioca, em semeadura de inverno, antecipando a colheita em apenas 3, 3 e 1 dia, em relação à da testemunha, respectivamente (Figura 5). A dessecação a partir dos 45 DAF não seria conveniente, pois, neste estádio, além do teor de água das sementes já se encontrar reduzido $\left(300 \mathrm{~g} \mathrm{~kg}^{-1}\right)$, a relação custo/benefício da dessecação não seria mais interessante, sugerindo estudo de análise econômica, antes de optar por esta prática.

\section{CONCLUSÕES}

A partir dos 35 dias após o florescimento, a produtividade do feijoeiro não foi afetada pela aplicação de paraquat, ao passo que o incremento das doses do dessecante provocou sua redução linear.

Não se recomenda a aplicação de paraquat em précolheita da cultura, a menos que a lavoura apresente maturação desuniforme e esteja infestada por plantas daninhas nesta ocasião.

\section{AGRADECIMENTOS}

À Fundação de Amparo à Pesquisa do Estado de São Paulo (FAPESP), pela bolsa de estudo concedida ao primeiro autor.

\section{REFERENCIAS}

Ambrosano JE, Wutke EB \& Bulisani EA (1996) Feijão. In: Raij BV, Cantarella H, Quaggio JA \& Furlani AMC (Eds.) Recomendações de adubação e calagem para o Estado de São Paulo. $2^{\mathrm{a}}$ ed. Campinas, Instituto Agronômico/Fundação IAC. p.194-195. (Boletim Técnico 100).

Brasil (2009) Regras para análise de sementes. Brasília, Ministério da Agricultura, Pecuária e Abastecimento. 399p.

Benavides MP, Gallego SM, Comba ME \& Tomaro ML (2000) Relationship between polyamines and paraquat toxicity in sunflower leaf discs. Plant Growth Regulation, 31:215-224.

Conab (2010) Acompanhamento de safra brasileira: Grãos, décimo levantamento, julho/2010. Brasília, CONAB. 43p.

Domingos M, Silva AA, Silva RF, Silva JF \& Cardoso AA (2001) Efeitos de dessecantes, da época de colheita, do enleiramento e da chuva simulada no rendimento e na qualidade fisiológica das sementes de feijão. Revista Ceres, 48:365-380.

Domingos P, Silva AA \& Silva RF (1997) Qualidade da semente de feijão afetada por dessecantes, em quatro estádios de aplicação. Revista Brasileira de Sementes, 19:275-282.

Doorenbos J \& Kassam AH (1979) Efectos del agua sobre el rendimiento de los cultivos. Roma, FAO. 212p. (Estudio FAO, Riego y Drenage, 33).

Ekmekci Y \& Terzioglu S (2005) Effects of oxidative stress induced by paraquat on wild and cultivated wheats. Pesticide Biochemistry and Physiology, 83:69-81.

Embrapa (2006) Sistema brasileiro de classificação de solos. $2^{\mathrm{a}}$ ed. Brasília, Embrapa-SPI, Rio de Janeiro, Embrapa Solos. 306p.
Fernández F, Gepts P \& López BN (1992) Etapas de desenvolvimento da planta de feijão. In: Empresa de Pesquisa Agropecuária e Difusão de Tecnologia de Santa Catarina. A cultura do feijão em Santa Catarina. Florianópolis, EPAGRI, 1992. p.53-73.

Inoue MH, Marchiori Júnior O, Braccini AL, Oliveira Júnior RS, Ávila MR \& Constantin J (2003) Rendimento de grãos e qualidade de sementes de soja após a aplicação de herbicidas dessecantes. Ciência Rural, 33:769-770.

Kappes C, Carvalho MAC \& Yamashita OM (2009) Potencial fisiológico de sementes de soja dessecadas com diquat e paraquat. Scientia Agraria, 10:001-006.

Kappes C, Orsi JVN, Jesus Júnior AM \& Carvalho MAC (2008) Efeitos dos dessecantes diquat e paraquat no potencial produtivo da cultura da soja. Cultura Agronômica, 17:57-67.

Lacerda ALS, Lazarini E, Sá ME \& Valério Filho WV (2005) Efeitos da dessecação de plantas de soja no potencial fisiológico e sanitário das sementes. Bragantia, 64:447-457.

Marchiori Júnior O, Inoue MH, Braccini AL, Oliveira Júnior RS, Avila MR, Lawder M \& Constantin J (2002) Qualidade e produtividade de sementes de canola (Brassica napus) após aplicação de dessecantes em pré-colheita. Planta Daninha, 20:253-261.

Miguel MH (2003) Herbicidas dessecantes: Momento de aplicação, eficiência e influência no rendimento e na qualidade de sementes de feijão. Tese de Doutorado. Escola Superior de Agricultura "Luiz de Queiroz", Piracicaba, 111p.

Pimentel Gomes F \& Garcia CH (2002) Estatística aplicada a experimentos agronômicos e florestais: Exposição com exemplos e orientações para uso de aplicativos. Piracicaba, FEALQ. 309 p.

Santos JB, Ferreira EA, Ferreira EM, Silva AA \& Ferreira LR (2005) Efeitos da dessecação de plantas de feijão sobre a qualidade de sementes armazenadas. Planta Daninha, 23:645-651.

Santos JB, Ferreira EA, Santos EA, Silva AA, Silva FM \& Ferreira LR (2004) Qualidade de sementes de feijão (Phaseolus vulgaris) após aplicação do carfentrazone-ethyl em pré-colheita. Planta Daninha, 22:633-639.

Silva AA, Domingos M \& Cardoso AA (1999) Efeitos do paraquat e da mistura paraquat + diquat, como dessecantes, aplicados em diferentes épocas, no rendimento e na qualidade fisiológica das sementes de feijão. Revista Ceres, 46:239-250.

Silva SC \& Didonet AD (2005) Clima. In: Cobucci T \& Biava M. (Eds.) Cultivo do feijão irrigado na região Noroeste de Minas Gerais. Santo Antônio de Goiás, Embrapa Arroz e Feijão, Campinas, Embrapa Informática Agropecuária. (Sistemas de Produção, 5).

Teixeira FF, Ramalho MAP \& Abreu AFB (1999) Genetic control of plant architecture in the common bean (Phaseolus vulgaris L.). Genetics and Molecular Biology, 22:577-582.

Teófilo EM, Andrade MJB, Fraga AC \& Souza IF (1996) Dessecação química na cultura do feijoeiro (Phaseolus vulgaris L.): efeitos sobre a produção de grãos. Ciência e Agrotecnologia, 20:425436.

Vargas L, Silva AA, Borém A, Rezende ST, Ferreira FA \& Sediyama T (1999) Resistência de plantas daninhas a herbicidas. Viçosa, Jard Produções Gráficas, 131p.

Zagonel J, Venancio WS \& Sousa Neto AM (2002) Eficácia do herbicida diquat na dessecação em pré-colheita da cultura do feijão. Revista Brasileira de Herbicidas, 3:17-21. 